\title{
Splenic marginal zone lymphoma: comprehensive analysis of gene expression and miRNA profiling
}

\begin{abstract}
Alberto J Arribas ${ }^{1}$, Cristina Gómez-Abad ${ }^{2}$, Margarita Sánchez-Beato ${ }^{3}$, Nerea Martinez ${ }^{4}$, Lorena DiLisio $^{4}$, Felipe Casado ${ }^{5}$, Miguel A Cruz ${ }^{6}$, Patrocinio Algara ${ }^{1}$, Miguel A Piris ${ }^{7}$ and Manuela Mollejo ${ }^{8}$

${ }^{1}$ Genetics Department, Virgen de la Salud Hospital, Toledo, Spain; ${ }^{2}$ Molecular Pathology Programme, Spanish National Cancer Research Centre, Madrid, Spain; ${ }^{3}$ Medical Oncology Department, Oncohematology Unit, Fundación Investigación Biomédica HU. Puerta de Hierro-Majadahonda, Madrid, Spain; ${ }^{4}$ Cancer Genomics Laboratory, Hospital Universitario Marqués de Valdecilla, Instituto de Formación e Investigación Marqués de Valdecilla (IFIMAV), Santander, Spain; ${ }^{5}$ Hematology Department, Virgen de la Salud Hospital, Toledo, Spain; ${ }^{6}$ Oncology Department, Virgen de la Salud Hospital, Toledo, Spain; ${ }^{7}$ Pathology Department, Hospital Universitario Marqués de Valdecilla, Instituto de Formación e Investigación Marqués de Valdecilla (IFIMAV), Santander, Spain and ${ }^{8}$ Pathology Department, Virgen de la Salud Hospital, Toledo, Spain
\end{abstract}

\begin{abstract}
Splenic marginal zone lymphoma is a small B-cell neoplasm whose molecular pathogenesis is still essentially unknown and whose differentiation from other small B-cell lymphomas is hampered by the lack of specific markers. We have analyzed the gene expression and miRNA profiles of 31 splenic marginal zone lymphoma cases. For comparison, 7 spleens with reactive lymphoid hyperplasia, 10 spleens infiltrated by chronic lymphocytic leukemia, 12 spleens with follicular lymphoma, 6 spleens infiltrated by mantle cell lymphoma and 15 lymph nodes infiltrated by nodal marginal zone lymphoma were included. The results were validated by qRT-PCR in an independent series including 77 paraffin-embedded splenic marginal zone lymphomas. The splenic marginal zone lymphoma miRNA signature had deregulated expression of 51 miRNAs. The most highly overexpressed miRNAs were $m i R-155, m i R-21, m i R-34 a, m i R-193 b$ and $m i R-100$, while the most repressed miRNAs were miR-377, miR-27b, miR-145, miR-376a and miR-424. MiRNAs located in 14q32-31 were underexpressed in splenic marginal zone lymphoma compared with reactive lymphoid tissues and other B-cell lymphomas. Finally, the gene expression data were integrated with the miRNA profile to identify functional relationships between genes and deregulated miRNAs. Our study reveals miRNAs that are deregulated in splenic marginal zone lymphoma and identifies new candidate diagnostic molecules for splenic marginal zone lymphoma.

Modern Pathology (2013) 26, 889-901; doi:10.1038/modpathol.2012.220; published online 22 February 2013
\end{abstract}

Keywords: marginal zone lymphoma; miRNA expression profile; therapeutic target

Splenic marginal zone lymphoma has been recognized by the World Health Organization Lymphoma Classification as a regular entity. ${ }^{1}$ Splenic marginal zone lymphoma is an uncommon form of small B-cell neoplasm infiltrating in the spleen, bone marrow and peripheral blood. It accounts for $<1 \%$ of all lymphoid neoplasms, in which the relative rarity of splenic marginal zone lymphomas is a

Correspondence: Dr AJ Arribas, PhD, Molecular Pathology Research Unit, Hospital Virgen de la Salud, Avda Barber, 30, Toledo, CP 45004, Spain.

E-mail: aarribas@sescam.jccm.es

Received 13 September 2012; revised 12 November 2012; accepted 14 November 2012; published online 22 February 2013 significant obstacle to their molecular investigation and identification of specific diagnostic markers. The most common genomic alteration in splenic marginal zone lymphoma is the $7 \mathrm{q} 31$ deletion (26-45\% of patients) ${ }^{2-4}$ involving the miRNA miR$29 b^{4,5}$ and others. Translocations involving the 14q32 band, in which the immunoglobulin heavy chain variable region $\left(\operatorname{IgV}_{H}\right)$ locus is located, have been detected infrequently in splenic marginal zone lymphoma ${ }^{6}$ in comparison with other non-Hodgkin lymphomas. ${ }^{7}$ Around half of splenic marginal zone lymphoma patients carry an increased load of $\mathrm{IgV}_{\mathrm{H}}$ somatic mutations, which some studies have found to be associated with improved prognosis. ${ }^{8}$ Analysis of gene expression profiles (GEPs) in 
splenic marginal zone lymphoma has revealed the deregulated expression of lymphoma oncogenes, such as $R H O H$ and TCL1A, identifying clinical subgroups and new therapeutic targets. ${ }^{9}$ Very recently, genome sequencing studies have identified recurrent mutations in the NOTCH2 gene that seem to be restricted to splenic marginal zone lymphoma among low-grade B-cell disorders. ${ }^{10,11}$ Nevertheless, the molecular pathogenesis of splenic marginal zone lymphoma is still poorly understood, and the data obtained so far suggest that miRNA could play a key role in the pathogenesis of the disease.

Although the diagnostic criteria for the recognition of splenic marginal zone lymphoma are clearly established in splenic tissue, this diagnosis often has to be performed in peripheral blood or bone marrow, where the diagnosis of splenic marginal zone lymphoma is often hindered by the lack of consistent markers differentiating it from chronic lymphocytic leukemia, follicular lymphoma and mantle cell lymphoma.

MiRNAs are 21- to 23-nt-long RNA molecules that regulate mRNA translation and, consequently, the expression of protein-coding genes. More than 1000 miRNAs have been identified in mammals, in which they regulate a range of biological functions, including cell differentiation and proliferation. B-cell differentiation is tightly regulated by miRNAs and the expression of characteristic sets of miRNAs distinguishes specific stages of B-cell differentiation and B-cell lymphoma main tumor types. ${ }^{12,13}$ The miRNA profile of splenic marginal zone lymphoma has been investigated by several groups, who have obtained interesting results related with $7 \mathrm{q}$ loss, hepatitis C virus presence or with normal spleen. ${ }^{4,5,14,15}$ Nevertheless, the miRNA changes in splenic marginal zone lymphoma are yet to be comprehensively described. We aimed to carry out an integrated genomics study to improve our understanding of the molecular mechanisms involved in the pathogenesis of splenic marginal zone lymphoma, and to suggest new targets, genes and miRNAs, with diagnostic and therapeutic potential.

\section{Patients and methods}

\section{Patients and Tissue Samples}

The series included 31 patients with splenic marginal zone lymphoma. Clinical information about these cases was retrieved from medical records, surgical pathology reports and referring clinicians (Table 1). For comparison purposes, we included a set of 35 spleen samples: 7 spleens with reactive lymphoid hyperplasia (reactive spleens), 10 spleens infiltrated by chronic lymphocytic leukemia, 12 spleens with follicular lymphoma and 6 spleens infiltrated by mantle cell lymphoma. To compare the miRNA expression profile between splenic and nodal marginal zone lymphoma, we included 15 lymph nodes infiltrated by nodal marginal zone lymphoma that were included in a previous study by our group. ${ }^{16}$

The main criterion for inclusion was the availability of frozen tissue from the diagnostic specimen in each case. Morphological examination and CD20 immunostaining revealed the cases in which at least $75 \%$ of the cells were tumoral in this study.

To validate the levels of miRNA profiles found by microarray analysis, quantitative reverse transcription-polymerase chain reaction (qRTPCR) studies were performed with formalin-fixed, paraffin-embedded tissues from an independent series including 141 cases: 77 splenic marginal zone lymphoma, 16 chronic lymphocytic leukemia, 20 follicular lymphoma, 22 mantle cell lymphoma and 6 reactive spleens.

All cases were provided by the Tumor Bank of the Hospital Virgen de la Salud (BioB-HVS, Toledo, Spain) and the CNIO Tumour Bank (Madrid, Spain). Cases were diagnosed on the basis of morphology, immunophenotypic and molecular findings according to the World Health Organization classification criteria. ${ }^{1}$ Research was performed under the supervision of the Institutional Review Board of the HVS, Toledo, Spain.

\section{Selection of B-cell Subsets}

B-cell populations were obtained by magnetic cell separation from 5 tumoral patients and 4 healthy donors undergoing routine hematological analysis. The splenic marginal zone lymphoma and non-tumoral B cells were recognized by CD19+ expression.

\section{RNA Isolation}

For GEP and miRNA hybridization, total RNA was isolated from 59 frozen tumoral blocks and 7 control samples from reactive spleens by TRIzol Reagent (Invitrogen, Paisley, UK) following the manufacturer's recommendations. The quality of the RNA produced was checked by $1 \%$ agarose electrophoresis. Cases with poor-quality RNA $\left(A_{260 / 280}\right.$ and $A_{260 / 230}$ ratios $<1.8$ measured in the NanoDrop; Thermo Scientific, Wilmington, USA) were discarded.

\section{Microarray Procedures: GEP and miRNA Hybridization}

RNA for GEP was hybridized on a Whole Human Genome Agilent $4 \times 44 \mathrm{~K}$ Oligonucleotide Microarray (Agilent Technologies, Santa Clara, CA, USA), as described elsewhere. ${ }^{17}$

The miRNA microarray experiments were done using the Agilent Human miRNA Microarray (V1), 
Table 1 Clinical characteristics of the splenic marginal zone lymphoma series of patients

\begin{tabular}{|c|c|c|c|c|c|c|c|c|}
\hline Case & Age/sex & $I G V H$ & $I D \%$ & $7 q$ & Treatment & Progression & Status & OS \\
\hline 1 & $52 / \mathrm{F}$ & VH4-34 & 100 & ND & $\mathrm{S}$ & NO & AWD & 26 \\
\hline 2 & ND & ND & ND & ND & ND & ND & ND & ND \\
\hline 3 & $70 / \mathrm{F}$ & VH3-30 & 98 & ND & S & NO & DOD & 25 \\
\hline 4 & $44 / F$ & VH3-30 & 95.9 & ND & $\mathrm{S}$ & YES & AWD & 24 \\
\hline 5 & $70 / \mathrm{M}$ & VH3-30 & 92.1 & ND & $\mathrm{S}$ & YES & AWD & 64 \\
\hline 6 & $66 / \mathrm{F}$ & NR & NR & ND & S & NO & AWD & 195 \\
\hline 8 & $73 / \mathrm{F}$ & VH1-2/VH3-30 & $94.7 / 100$ & YES & $\mathrm{S}$ & NO & AWD & 22 \\
\hline 10 & $60 / \mathrm{M}$ & VH1-2 & 99.1 & YES & S & NO & AWD & 67 \\
\hline 11 & $50 / \mathrm{M}$ & VH1-2 & 98.21 & YES & S, CHT & NO & AWD & 30 \\
\hline 12 & $55 / \mathrm{M}$ & VH1-2 & 97.3 & YES & ND & NO & AWD & 81 \\
\hline 13 & $67 / \mathrm{M}$ & NR & NR & ND & ND & ND & ND & ND \\
\hline 14 & $64 / \mathrm{F}$ & VH1-2/VH3-8 & $97.21 / 96.41$ & YES & ND & YES & $\mathrm{DXT}$ & 61 \\
\hline 15 & $66 / \mathrm{M}$ & VH4-39/VH3-74 & $100 / 100$ & YES & ND & YES & DXT & 57 \\
\hline 17 & $68 / \mathrm{M}$ & VH2-70/VH3-30 & ?/93.5 & ND & ND & YES & DXT & 78 \\
\hline 18 & $63 / \mathrm{M}$ & VH1-18/VH3-3 & $99.5 / 100$ & YES & ND & YES & DXT & 10 \\
\hline 19 & $72 / \mathrm{F}$ & VH1-2 & 93.3 & YES & ND & NO & AWD & 24 \\
\hline 20 & $70 / F$ & VH1-2 & 96.4 & YES & ND & YES & AWD & 76 \\
\hline 21 & $65 / F$ & VH4-34 & 96.35 & YES & ND & NO & AWD & 53 \\
\hline 22 & $61 / \mathrm{M}$ & VH1-2 & 93.4 & NO & ND & YES & AWD & 42 \\
\hline 23 & $70 / \mathrm{F}$ & VH3-30 & 95.98 & NO & ND & YES & DXT & 18 \\
\hline 24 & $63 / \mathrm{F}$ & VH6-1 & 94.5 & ND & ND & NO & AWD & 13 \\
\hline 25 & $59 / \mathrm{M}$ & NR & NR & ND & ND & NO & AWD & 34 \\
\hline 26 & $72 / \mathrm{F}$ & NR & NR & ND & ND & NO & DOD & 54 \\
\hline 27 & $76 / \mathrm{F}$ & NR & NR & ND & ND & YES & DXT & 92 \\
\hline 28 & $67 / F$ & VH1-2 & 99.55 & YES & ND & YES & AWD & 53 \\
\hline 29 & $74 / \mathrm{M}$ & VH1-2 & 100 & YES & ND & YES & DXT & 3 \\
\hline 30 & $66 / F$ & VH1-2 & 99.1 & YES & ND & YES & $\mathrm{DXT}$ & 22 \\
\hline 31 & ND & NR & NR & ND & ND & ND & ND & ND \\
\hline
\end{tabular}

Abbreviations: F, female; M, male; ND, no data; NR, no rearrangement; ID, identity frequency; S, splenectomy; CHT, chemotherapy; D, dead; DOD, dead of disease; DXT, dead, non-lymphoma related; AWD, alive with disease.

SMZL patients had a median age of 64.7 years, ranging from 44 to 76 years; $54 \%$ of them were women.

$8 \times 15 \mathrm{~K}$ (Agilent Technologies). For each tissue sample, $100 \mathrm{ng}$ total RNA were hybridized with the miRNA array and further processed as previously described. ${ }^{18}$

\section{Microarray Data Analysis: GEP, miRNA, B-cell Subsets}

The background subtraction of GEP microarray data was carried out using GEPAS 4.0 (http://gepas. bioinfo.cipf.es/). The data set was normalized by lowess within-array normalization and quantile between-array normalization, and then preprocessed. For miRNA profiling, microarray background subtraction was carried out using the normexp tool available in Bioconductor's limma package (http://www.bioconductor.org). To normalize this data set, loess within-array normalization and quartile between-array normalization were performed. ${ }^{19}$

We used $t$-tests (http://pomelo2.bioinfo.cnio.es/) to compare the expression of the splenic marginal zone lymphoma gene and miRNA signatures with that of the reactive spleens and with the other low-grade B-cell lymphoma types (chronic lymphocytic leukemia, follicular lymphoma and mantle cell lymphoma). In this comparison with other lymphomas, we used a $t$-test to compare splenic marginal zone lymphoma cases with other lymphoma samples (all treated as a single class). In all these comparisons, the genes and miRNAs with FDR $<0.05$ were considered significant.

For GEP signatures and miRNA signatures we used values of FDR $<0.01$ and $<0.05$, respectively, to indicate significance.

The t-statistic was calculated in the gene set enrichment analysis (GSEA) (http://www.broad. mit.edu/gsea/) to identify the pathways and functional groups enriched in the splenic marginal zone lymphoma signature. The GSEA gene sets used were selected from a curated version of the Biocarta, KEGG and CCG pathway databases, as previously described. ${ }^{20}$ The gene sets with values of $P<0.05$ or FDR $<0.25$ were considered to be enriched and potentially relevant in each case.

\section{MiRNA Target Prediction and miRNA Target Correlation}

We followed the previously described procedure ${ }^{21}$ to identify associations between differentially expressed miRNAs $(F D R<0.05)$ and gene expression signatures $(\mathrm{FDR}<0.05)$. The GSEA (Pearson correlation) was used to test the enrichment of gene sets related to each corresponding miRNA. Those with values of $P<0.05$ and $\mathrm{FDR}<0.25$ were 
considered to be enriched in each case. Gene target prediction for miRNAs of splenic marginal zone lymphoma signature were obtained using the TargetScan algorithm (Release 5.2) in conjunction with the mir2disease on-line database (http://www. mir2disease.org/).

\section{Quantitative Real-Time RT-PCR Analysis}

To validate miRNA microarray data we carried out a qRT-PCR assay. Total RNA was extracted from formalin-fixed, paraffin-embedded tissues sections of an independent patient group following the manufacturer's instructions and using a miRNeasy FFPE Kit (Qiagen, Valencia, CA, USA).

qRT-PCR experiments were performed on selected miRNAs using TaqMan probes (Applied Biosystems, Foster City, CA, USA), as previously described. ${ }^{9,21}$ The relative degree of change for each miRNA was calculated using the $R Q=2^{-\Delta C t}$ method, where $\Delta \mathrm{Ct}=\left(\mathrm{Ct}_{\mathrm{miRNA}}-\mathrm{Ct}_{\mathrm{Ub}}\right)$, and with an RNU6B endogenous control. Ct values $>32$ were considered beyond the limit of detection.

Results were analyzed with $t$-tests and one-way ANOVAs (calculated in SPSS v.17.0). miRNAs with values of $P<0.05$ were considered statistically significant.

\section{Results}

\section{miRNA Signature in Splenic Marginal Zone Lymphoma}

The miRNA signature in splenic marginal zone lymphoma, comprising the miRNAs differentially expressed in splenic marginal zone lymphoma relative to reactive spleen (FDR $<0.05 ; t$-test), included 51 miRNAs, 9 of which were overexpressed and 42 were repressed. Within the overexpressed miRNAs we found miRNAs that are involved in B-cell development (eg, miR-155) and miRNAs that are deregulated in cancer (eg, miR-21, miR-34a and miR-193b). Among the underexpressed miRNAs we found a high number of miRNAs located in 14q32 (14 of 52 miRNAs, $\sim 27 \%$ of the signature), such as miR-377, miR-376a and miR-136, and other relevant miRNAs, like miR-24, miR-27b (both located in the 9q22 band) and miR-145 (Table 2; Figure 1).

These findings prompted us to compare the expression of these 14q32 miRNAs of the signature with those found in other lymphomas involving the spleen and nodal marginal zone lymphoma. Interestingly, we found that some of the miRNAs in 14 q32 were also significantly repressed in splenic marginal zone lymphoma compared with nodal marginal zone lymphoma. Although the values were not significant, these miRNAs in $14 \mathrm{q} 32$ had a lower level of expression in splenic marginal zone lymphoma than chronic lymphocytic leukemia, follicular lymphoma, and mantle cell lymphoma, with less than onefold change. Ultimately, miRNAs in 14q32 was also repressed in lymph nodes infiltrated by splenic marginal zone lymphoma. No miRNA in $7 \mathrm{q}$ appears in the signature, even though miR-29a and miR-29b repressed in splenic marginal zone lymphoma have been described ${ }^{4,5}$ (Table 2; Figure 2).

\section{Comparison of Splenic Marginal Zone Lymphoma B Cells and Normal B Cells}

Taking into account the essential role of the stromal microenvironment in low-grade lymphomas, we took another approach to compare CD19+ B cells isolated from peripheral blood of splenic marginal zone lymphoma patients with those from healthy donors. This enabled us to identify some of the most important miRNAs in the splenic marginal zone lymphoma miRNA signature, both upregulated (miR-21 and miR-193b) and downregulated (miR-483, miR-485-3p and miR-328) (Table 2; Supplementary Table 4). It is of particular note that miR-29b and miR-592, located at 7q32, are repressed in splenic marginal zone lymphoma B cells compared with healthy donors (Supplementary Table 4).

\section{Integration of miRNA and GEP Data}

Although the GEP in splenic marginal zone lymphoma has been previously described, ${ }^{9,22,23}$ as we are now interested in identifying the association between miRNA signature and GEP, the same series used in the miRNAs was also hybridized in GEP. Therefore, we determined the GEP of splenic marginal zone lymphoma relative to reactive spleen using a $t$-test $(F D R<0.01)$ and GSEA software $(P<0.05$, FDR $<0.25)$. The GEP signature determined in splenic marginal zone lymphoma comprised 753 genes, 194 of them upregulated and 559 repressed. Among the overexpressed genes we found integrins $(C D 40)$, BCR signaling genes (SYK, BLNK, NFATC1), proliferation-related genes (MUM1, RHOH, AIM2), interleukins (IL2RA, IL7, IL6, IL21), anti-apoptotic genes (BCL2, BCL2L10, FOXP1, BIRC3), TNF signaling (CD70, TNFRSF9) and normal marginal zone-related genes (TACI, CD44, IL2RA, MMP12). Among the repressed genes we found genes located in $7 \mathrm{q}$ (MEST, MET, PTN), others with important functions in B cells (FCGR3A, FCGR3B, TNFAIP1, TNFAIP2, CXCL1, CXCL12), and cell adhesion-related genes (TGFBI and ICAM2). GEP data in SMZL are shown in Supplementary Table 2.

The GSEA analysis revealed the enrichment of pathways related to cell survival, such as NF$\kappa \mathrm{B}$, BAFF signaling and cell cycle, and crucial B-cell pathways, such as memory B-cell-related genes $\left(\mathrm{IgM}^{+} \mathrm{IgD}^{+} \mathrm{CD}_{27}^{+}\right)$, PRDM1 signaling and B-cell receptor genes (Supplementary Table 3). 
Table 2 MiRNA expression profile in splenic marginal zone lymphoma

\begin{tabular}{|c|c|c|c|c|c|c|c|c|c|c|c|}
\hline \multirow[t]{2}{*}{$\operatorname{miRNA}$} & \multirow[t]{2}{*}{ Cytoband } & \multicolumn{2}{|c|}{$S M Z L$ vs. $R L H$} & \multicolumn{4}{|c|}{ SMZL vs. other lymphomas } & \multicolumn{2}{|c|}{$S M Z L$ vs. NMZL } & \multicolumn{2}{|c|}{$B$ cells } \\
\hline & & $F D R$ & $F C$ & $F D R$ & $\begin{array}{c}F C \\
\text { (vs. } F L)\end{array}$ & $\begin{array}{c}F C \\
\text { (vs. } C L L \text { ) }\end{array}$ & $\begin{array}{c}F C \\
\text { (vs. } M C L)\end{array}$ & $F D R$ & $F C$ & $F D R$ & $F C$ \\
\hline hsa-miR-155 & $21 q 21.3$ & 0.0001 & 1.3636 & NS & -0.6234 & -1.9369 & -0.7545 & 0.0075 & 0.8876 & NS & 1.0121 \\
\hline hsa-miR-34a & $1 \mathrm{p} 36.22$ & 0.0013 & 1.281 & NS & -0.5482 & -0.9769 & -1.2861 & 0.0073 & -0.8094 & NS $(0.0784)$ & 1.392 \\
\hline hsa-miR-100 & 11q24.1 & 0.0028 & 1.1235 & NS & -0.7022 & -0.9698 & -1.4994 & 0.0012 & 1.2583 & NS & 0.4678 \\
\hline hsa-miR-193b & $16 \mathrm{p} 13.12$ & 0.0216 & 1.0595 & NS & -0.7951 & -0.4008 & -1.8453 & NS & -0.5294 & 0.035 & 1.6673 \\
\hline hsa-miR-330 & $19 q 13.32$ & 0.001 & 0.8598 & NS & -0.7498 & -0.9477 & -1.0091 & 0.0008 & 1.0633 & NS (0.0539) & 1.5244 \\
\hline hsa-miR-21 & $17 q 23.2$ & 0.0474 & 0.8513 & 0.0049 & -1.1313 & -1.0129 & -1.3443 & 0 & -2.1378 & 0.0132 & 1.9599 \\
\hline hsa-miR-26b & 2q35 & NS & 0.2715 & 0.041 & -0.3368 & -1.4802 & -0.8624 & 0.0005 & -1.0987 & 0.0329 & -1.687 \\
\hline hsa-miR-19b & $13 q 31.3$ & NS & 0.1102 & 0.0499 & -0.3911 & -1.1701 & -1.3954 & 0.0006 & -0.8801 & NS & -1.3312 \\
\hline hsa-miR-660 & Xp11.22 & NS & 0.0263 & 0.0225 & -0.7694 & -1.0851 & -1.0885 & NS & -0.4423 & NS & 0.6627 \\
\hline hsa-miR-448 & Xq23 & NS & -0.1061 & 0.033 & -0.762 & -1.0343 & -0.9973 & 0.0001 & -0.9103 & NS & -0.4552 \\
\hline hsa-miR-646 & $20 q 13.33$ & NS & -0.1896 & 0.033 & -0.7637 & -1.027 & -1.0011 & 0 & -1.3027 & NS & -0.2437 \\
\hline hsa-miR-323 & $14 q 32.31$ & NS & -0.3022 & 0.0447 & -0.784 & -1.0144 & -1.0373 & NS & 0.2477 & NS & 0.6538 \\
\hline hsa-miR-567 & 3q13.2 & NS & -0.3514 & 0.041 & -0.8072 & -1.0267 & -1.0057 & 0.0315 & -0.4447 & NS & -0.9589 \\
\hline-589 & p22.1 & 0.0334 & -0.4116 & 0.0447 & -0.78 & -1.03 & -1.03 & NS & -0.3662 & NS & -0.1161 \\
\hline iiR-381 & $14 q 32.31$ & 0.0022 & -0.8884 & NS & -0.8363 & -1.0544 & -1.03 & 0.0394 & -1.0007 & NS & -1.3213 \\
\hline hsa-miR-494 & $4 q 32.31$ & 0.0102 & -0.9253 & NS & -0.1518 & -0.3148 & -0.4096 & NS & 0.5589 & NS & -0.1063 \\
\hline hsa-miR-382 & $14 \mathrm{q} 32.31$ & 0.0024 & -0.9511 & NS & -0.7663 & -1.1678 & -1.1157 & NS & -0.325 & NS & 0.3914 \\
\hline hsa-miR-154 & $14 q 32.31$ & 0.0001 & -1.0173 & NS & -0.8407 & -1.1529 & -1.0722 & NS & 0.2216 & NS & -0.6378 \\
\hline hsa-miR-376b & $14 \mathrm{q} 32.31$ & 0.0081 & -1.0242 & NS & -0.8409 & -1.1961 & -1.0566 & 0.0047 & -1.7553 & NS & 0.3983 \\
\hline hsa-1 & $\mathrm{q} 32.31$ & 0.0004 & -1.0356 & & -0.8425 & -1.071 & -1.0 & NS & -0.0101 & NS & 0.9009 \\
\hline hsa- & 2.31 & 0.004 & -1.2176 & NS & -0.7677 & -1.2333 & -1.3005 & 0.0001 & -1.3158 & NS & 0.7175 \\
\hline hsa-miR-758 & $14 q 32.31$ & 0 & -1.2837 & NS & -0.8111 & -1.0247 & -0.9909 & 0.0102 & -0.5757 & NS & -1.5249 \\
\hline hsa-miR-199a & $19 \mathrm{p} 13.2$ & 0.0005 & -1.2864 & NS & -0.7517 & -1.0731 & -1.4343 & 0 & -1.1909 & NS & 0.8821 \\
\hline hsa-miR-376a & $14 \mathrm{q} 32.31$ & 0.0009 & -1.3704 & NS & -0.7113 & -1.4976 & -1.3556 & 0.0195 & -1.2118 & NS & 0.846 \\
\hline hsa-miR-136 & $14 q 32.31$ & 0.0009 & -1.4854 & NS & -0.7217 & -1.1304 & -1.0163 & 0.0309 & 0.6645 & NS & 0.5251 \\
\hline hsa-miR-379 & $14 \mathrm{q} 32.31$ & 0 & -1.4966 & $\mathrm{~N}$ & -0.8855 & -1.0778 & -1.0051 & NS & 0.1304 & NS & 0.8097 \\
\hline iR-145 & 5q32 & 0.0004 & -1.5099 & $\mathrm{~N}$ & -1.128 & -0.8589 & -1.3141 & 0.003 & 0.9025 & NS & 0.983 \\
\hline hsa-miR-338 & $17 q 25.3$ & 0.0004 & -1.6084 & NS & -0.9872 & -1.1076 & -1.0284 & 0.0007 & -1.5367 & NS & 1.4012 \\
\hline hsa-miR-107 & $10 \mathrm{q} 23.31$ & 0 & -1.6811 & NS & -0.5584 & -0.8375 & -1.1204 & 0.0157 & -0.6025 & NS & -0.0679 \\
\hline hsa-miR-27b & $9 q 22.32$ & 0 & -1.6847 & NS & -0.6594 & -1.2939 & -0.9624 & 0.0001 & -1.6646 & NS & 0.7803 \\
\hline hsa-miR-24 & 9q22.32 & 0 & -1.7407 & NS & -0.681 & -0.8085 & -1.0673 & 0.0001 & -1.2365 & NS & 0.9969 \\
\hline hsa-miR-377 & $14 \mathrm{q} 32.31$ & 0 & -1.8081 & NS & -0.8439 & -1.3491 & -1.132 & 0.0037 & -1.8887 & NS & 0.5973 \\
\hline hsa-miR-328 & 16q22.1 & 0.0001 & -0.9722 & NS & -0.1321 & -0.0142 & 0.0541 & 0.0062 & -1.3057 & 0.0222 & -1.809 \\
\hline hsa-miR-485-3p & $14 q 32.31$ & 0.0026 & -1.0844 & NS & 0.2086 & 0.3138 & 0.3265 & NS & NS & 0.0198 & -1.8431 \\
\hline hsa-miR-483 & 11p15,5 & 0.0059 & -1.2378 & NS & 0.249 & 0.2958 & 0.3923 & 0.0276 & -1.5169 & 0.0084 & -2.0841 \\
\hline hsa-miR-339 & 7p22.3 & NS & -0.659 & NS & -0.1099 & -0.4604 & 0.8266 & NS & NS & 0.0059 & -2.1783 \\
\hline
\end{tabular}

SMZL vs. RLH columns corresponding to a $t$-test between splenic marginal zone lymphoma and reactive spleen. The data from SMZL vs. Other Lymphomas columns correspond to a $t$-test comparing splenic marginal zone lymphoma with follicular lymphoma, chronic lymphocytic leukemia and mantle cell lymphoma, considered as a single class. SMZL vs. NMZL columns correspond to a $t$-test comparing the two marginal zone classes. The B-cell column corresponds to a $t$-test with B-cell data, obtained from isolated CD19+ B cells from peripheral blood of splenic marginal zone lymphoma patients and healthy donors. FDR is the false discovery rate. FC is the $n$-fold change (log ${ }_{2}$ scale) difference between the corresponding averages of classes. NS, not significant.

The GEP data were integrated with the miRNA profile using a TargetScan prediction algorithm and Pearson correlation (GSEA software) to identify functional relationships between genes and deregulated miRNAs. Among the upregulated splenic marginal zone lymphoma genes targeted by downregulated miRNAs, we found genes relevant in B-cell survival signaling, such as $S Y K, C D 40$, BCL2, CD44, AIM2, FOXP1, MUM1 (IRF4) and $\mathrm{RHOH}$. Downregulated miRNAs targeting these genes were miR-145, miR-27b, miR-376a and miR377 (Tables 2 and 3; Figure 3; Supplementary Table 2).

Conversely, among the downregulated splenic marginal zone lymphoma genes targeted by upregulated miRNAs, we found apoptosis regulators such as TNFAIP1 and TNFAIP2 that are predicted to be regulated by overexpressed miRNAs such as miR-34a and miR-193b. The overexpressed miR-155 could regulate the PLEKHG5 gene, which is involved in the NF- $\kappa \mathrm{B}$ signaling pathway. Similarly, the high level of miR-21 could contribute to the expression of TSPYL5, which is implicated in PTEN-AKT signaling (Tables 2 and 3; Figure 3; Supplementary Table 2).

GSEA was done to determine the enriched pathways related to the most relevant miRNAs in the study. It revealed significant gene sets and pathways with a crucial role in B-cell survival, such as NF- $\kappa \mathrm{B}$ signaling, CD40 signaling, interleukins and inflammatory pathways, cell cycle and memory B-cell genes, to be associated with the expression of miR-155, miR-34a and miR-21 (Table 4; Figure 3). 


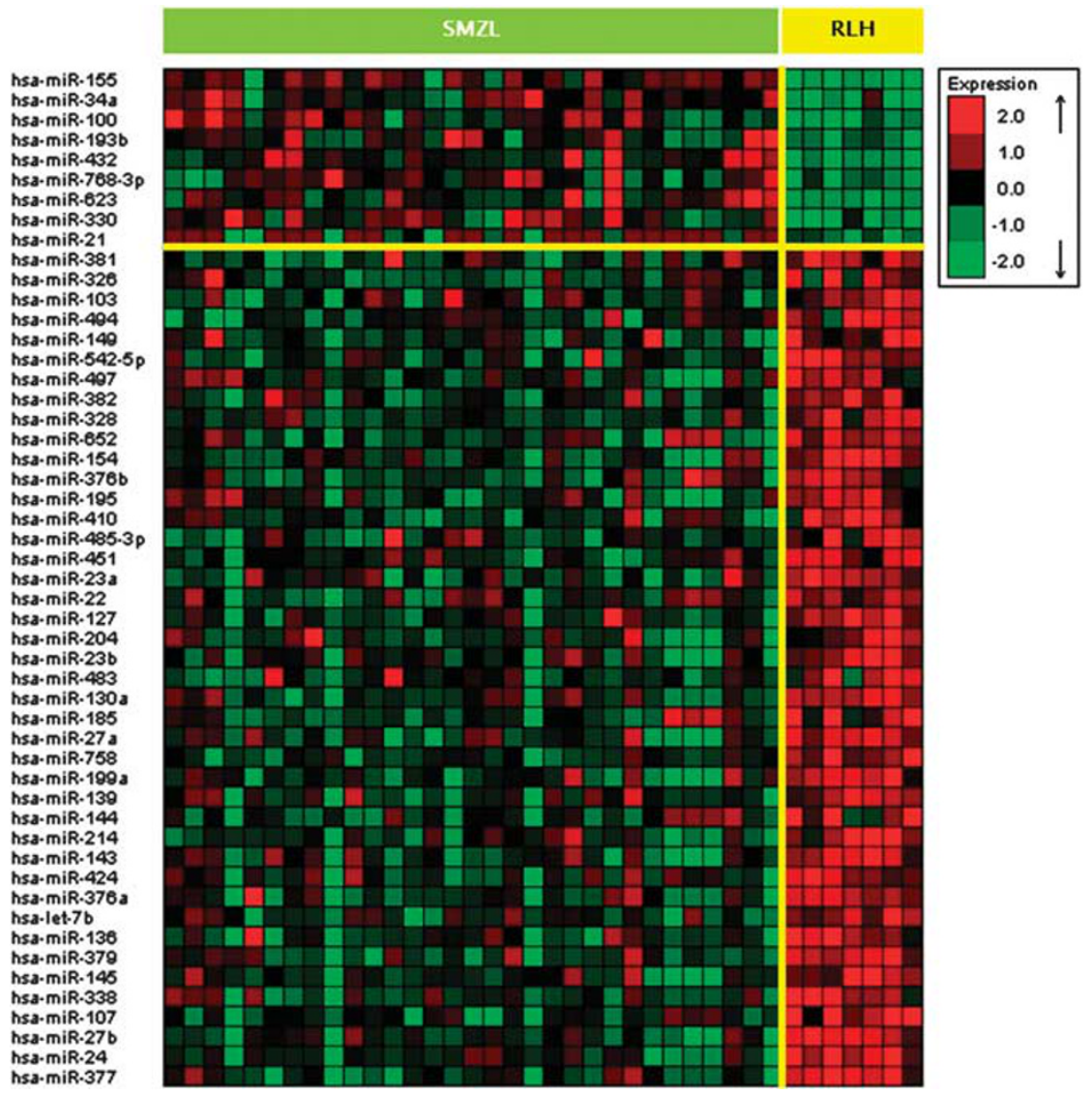

Figure 1 Splenic marginal zone lymphoma miRNA signature. Hierarchical clustering of the complete splenic marginal zone lymphoma miRNA signature: 52 miRNAs with FDR $<0.05$ and -0.85 - to 0.85 -fold change in a $t$-test comparison with RLH (http://pomelo2.bioinfo.cnio.es/). Red and green indicate high- and low-level expression, respectively. SMZL, splenic marginal zone lymphoma; RLH, reactive lymphoid hyperplasia in the spleen.

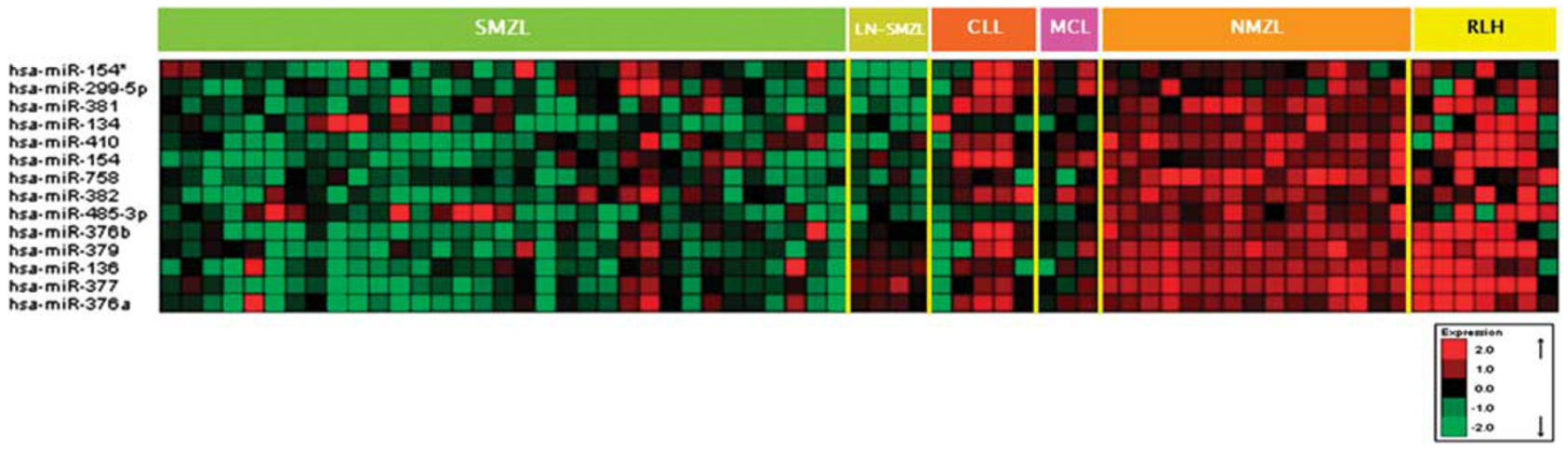

Figure 2 MiRNAs in 14q32. The splenic marginal zone lymphoma miRNA signature contains 14 repressed miRNAs located in $14 q 32$ chromosomal band ( $27 \%$ of the signature). These had a lower level of expression in splenic marginal zone lymphoma than in other classes: lymph node infiltrated by splenic marginal zone lymphoma (LN-SMZL), spleens infiltrated by chronic lymphocytic leukemia (CLL) and by mantle cell lymphoma (MCL), nodal marginal zone lymphoma (NMZL) and non-tumoral spleens (RLH).

\section{Comparison Between Splenic and Nodal Marginal Zone Lymphomas}

We also studied the miRNA expression patterns of splenic marginal zone lymphoma relative to nodal marginal zone lymphoma obtaining 44 miRNAs differentially expressed between these subtypes of marginal lymphoma: These included 19 miRNAs from the splenic marginal zone lymphoma signature, some of which were the most important miRNAs, such as miR-21, miR-155, miR-100, miR27b, miR-376a and miR-377. Similarly, among the miRNAs with increased expression in nodal marginal zone lymphoma were several already known to be overexpressed in this lymphoma type, such as miR$199 a^{16}$ (Table 2; Supplementary Table 5). 
Table 3 Gene target prediction for the most significant miRNAs in the assay

\begin{tabular}{|c|c|c|c|c|c|c|}
\hline miRNA Signature & $\operatorname{miRNA}$ & $F D R$ & $F C$ & $\begin{array}{l}\text { Validated targets } \\
\text { (published studies) }\end{array}$ & $\begin{array}{l}\text { Prediction targets } \\
\text { (TargetScan) }\end{array}$ & GEP signature \\
\hline \multirow[t]{4}{*}{$\begin{array}{l}\text { Upregulated } \\
\text { miRNAs }\end{array}$} & hsa-miR-155 & 0.0001 & 1.3636 & $\begin{array}{l}\text { AGTR1, SAMD1, SMAD5, BCL2 } \\
\text { SHIP1, HIF, ETS1, AID, RHOA }\end{array}$ & $\begin{array}{l}\text { PLEKHG5, PTN, RHOBTB1, } \\
\text { RAPGEF5, GDPD5 }\end{array}$ & \multirow[t]{4}{*}{$\begin{array}{l}\text { Downregulated } \\
\text { genes }\end{array}$} \\
\hline & hsa-miR-34a & 0.0013 & 1.281 & $\begin{array}{l}\text { E2F3, CCND1, ARAF, AXL, MEK1, } \\
\text { MET, PIK3R2 } \\
\text { CCND3, MCM2, MCM5, PLK1, } \\
\text { SMAD4, WNT1, JAG1 }\end{array}$ & $\begin{array}{l}\text { CCND1, TNFAIP1, CDH4, } \\
\text { RAPGEF5 }\end{array}$ & \\
\hline & hsa-miR-193b & 0.0216 & 1.0595 & $\begin{array}{l}\text { MCL1, CCND1, 14-3-3, SHMT2, } \\
\text { AKR1C2 }\end{array}$ & $\begin{array}{l}\text { CCND1, TNFAIP1, PKD2L1, } \\
\text { RAPGEF5, CD160 }\end{array}$ & \\
\hline & hsa-miR-21 & 0.0474 & 0.8513 & $\begin{array}{l}\text { PTEN,TPM1, PDCD4, CDC25A, } \\
\text { LRRFIP1, WNT1, JAG1 }\end{array}$ & $\begin{array}{l}\text { TSPYL5, TGFBI, RAPGEF5, FCGR3B } \\
\text { ITGA8, GDPD5, CD160 }\end{array}$ & \\
\hline \multirow[t]{4}{*}{$\begin{array}{l}\text { Downregulated } \\
\text { miRNAs }\end{array}$} & hsa-miR-376a & 0.0009 & -1.3704 & unknown & $\begin{array}{l}\text { CD44, DLEU1, MUM1, IL2RA } \\
\text { IL7, IRTA4, FOXP1 }\end{array}$ & \multirow[t]{4}{*}{ Upregulated genes } \\
\hline & hsa-miR-145 & 0.0004 & -1.5099 & FLJ21308, C-MYC & $\begin{array}{l}\text { CD44, NFATC1, DLEU1, MUM1 } \\
\text { LIMK1, IL6, CD40, FOXP1 }\end{array}$ & \\
\hline & hsa-miR-27b & 0 & -1.6847 & $\begin{array}{l}C Y P 1 B 1, N O T C H 1 \\
N F-\kappa B \text { (lipopolysaccharide-induced } \\
\text { activation) }\end{array}$ & $\begin{array}{l}\text { CD44, NFATC1, SYK, PLA2G2D, } \\
\text { BCL2L10, DLEU1 } \\
\text { MUM1, LIMK1, TNFRSF9, IRTA1, } \\
\text { RHOH, AIM2, FOXP1 }\end{array}$ & \\
\hline & hsa-miR-377 & 0 & -1.8081 & $\begin{array}{l}\text { HO-1 (in combination with } \\
\text { hsa-miR-217) }\end{array}$ & $\begin{array}{l}\text { SYK, BCL2L1O, BCL2, DLEU1, } \\
\text { FCGR } 2 B, F O X P 1\end{array}$ & \\
\hline
\end{tabular}

The validated targets column refers to experimentally validated mRNA targets of the respective miRNAs selected from literature while the prediction targets are the predicted mRNAs according to the TargetScan algorithm (Release 5.2) in the mir2disease on-line database (http://www.mir2disease.org/). The miRNAs and predicted target genes are those of the splenic marginal zone lymphoma signature.

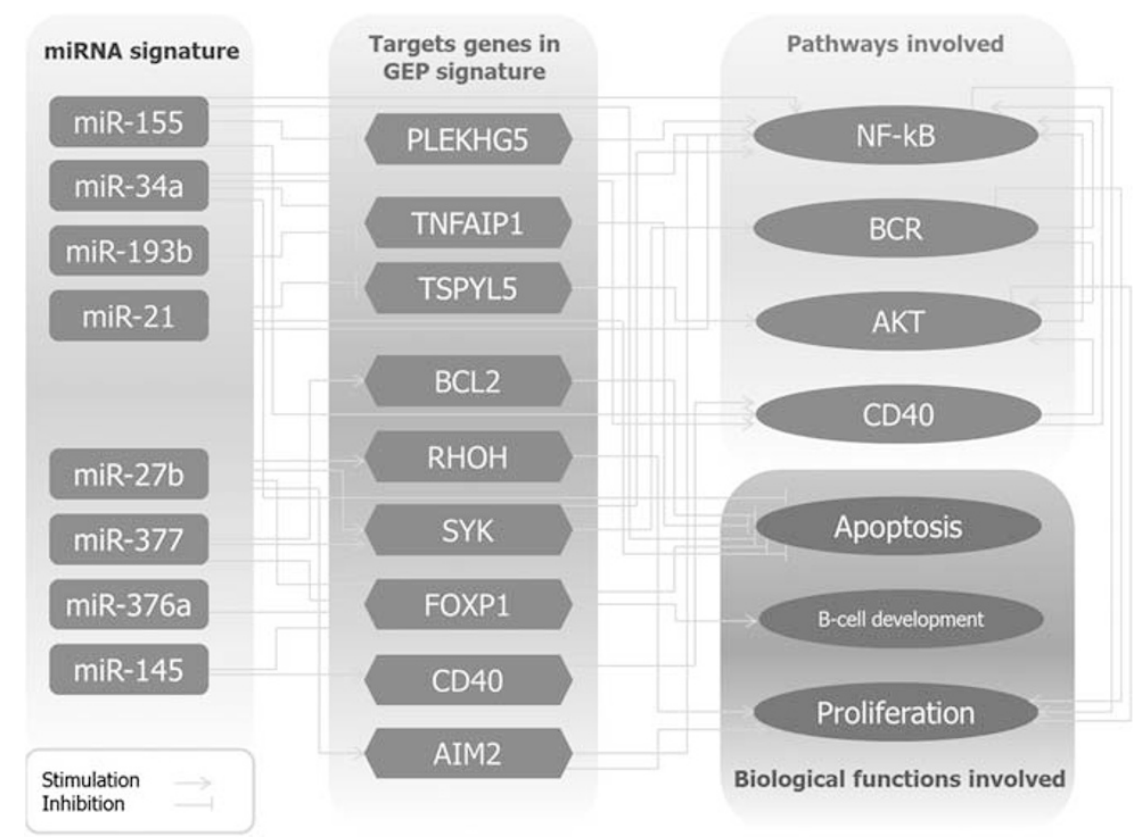

Figure 3 Representation of the most important miRNAs in the signature with connections to pathways and biological functions involved. The connections between upregulated and downregulated miRNAs with corresponding target genes and involved target pathways are shown. The links between miRNAs and genes corresponding to prediction targets by TargetScan algorithm; the junctions within genes and pathways and biological functions are based on literature and on-line databases, while those between miRNAs and pathways and functions reflect positive Pearson correlations from GSEA.

Supervised clustering of the splenic marginal zone lymphoma miRNA signature (SOTA algorithm, Pearson correlation) was used to differentiate between splenic marginal zone lymphoma cases in the spleen, lymph node infiltrated by splenic marginal zone lymphoma and nodal marginal zone lymphoma. Interestingly, lymph nodes infiltrated by splenic marginal zone lymphoma clustered with the splenic samples and not with the nodal cases (Figure 4). 
Splenic Marginal Zone Lymphomas vs. Other Low-Grade B-Cell Lymphomas in the Spleen

To determine those genes and miRNAs with differential expression between SMZL and other low-grade B-cell lymphomas in the spleen (chronic lymphocytic leukemia, follicular lymphoma and mantle cell lymphoma), we carried out a $t$-test, in which we found 357 genes and 9 miRNAs that were significantly deregulated (FDR $<0.05)$. This enabled us to predict targets in silico.

The GEP comparison confirmed the stronger expression of CD200 and TCL1A in chronic lymphocytic leukemia, the expression of germinal center markers BCL6, CD10 and GCTE1 in follicular lymphoma, and of HDGFRP3 in mantle cell lymphoma. The differentially expressed miRNAs included miR-21, miR-19b and miR-660, all of

Table 4 GSEA Pearson analysis

\begin{tabular}{lccc}
\hline GSEA gene sets & $\begin{array}{c}\text { miR-155 } \\
\text { FDR }\end{array}$ & $\begin{array}{c}\text { miR-34a } \\
\text { FDR }\end{array}$ & $\begin{array}{c}\text { miR-21 } \\
F D R\end{array}$ \\
\hline Memory B cells IgMIgDCD27 & 0.127 & NS & 0.174 \\
B-cell-T-cell calcium signaling & 0.067 & 0.024 & 0.023 \\
NF- $\kappa$ B target gene & 0.039 & 0.016 & 0.027 \\
NF- $\kappa$ B total pathway & 0.123 & 0.04 & 0.036 \\
CD40 during GC development & 0.065 & 0.078 & NS \\
Integrin pathway & NS & NS & 0.136 \\
IL2 pathway & 0.113 & 0.179 & NS \\
IL2RB pathway & 0.077 & NS & 0.184 \\
IL3 pathway & NS & 0.165 & NS \\
IL6 pathway & 0.108 & 0.154 & 0.094 \\
IL12 pathway & 0.129 & 0.175 & 0.029 \\
Inflammatory cytokine pathway & NS & 0.149 & 0.151 \\
T-cell cytokine signaling & 0.099 & 0.162 & 0.025 \\
RHO pathway & 0.162 & NS & 0.137 \\
TNFR2 pathway & 0.081 & 0.018 & 0.245 \\
JAK-STAT2 pathway & 0.122 & NS & 0.031 \\
JAK-STAT2 receptors & 0.111 & 0.146 & 0.023 \\
G2 pathway & 0.121 & NS & 0.056 \\
Cell cycle & 0.118 & 0.197 & 0.149 \\
Death pathway & 0.139 & 0.127 & 0.138 \\
& & & \\
\hline
\end{tabular}

Significant $(F D R<0.25)$ Pearson correlations associating upregulation of the most relevant overexpressed miRNAs in the assay with the enrichment of crucial B cells pathways and tumorigenesis-involved signaling pathways. which were repressed in splenic marginal zone lymphoma relative to other low-grade B-cell lymphomas and had been previously identified as being deregulated in lymphoma cells.

In splenic marginal zone lymphoma, we found upregulated genes related to normal marginal zone, such as TACI (TNFRSF13B), interleukins (IL6, IL7R), relevant kinases, such as PIP5K2A and EIF2AK2, and genes already described in the splenic marginal zone lymphoma GEP, such as MMP9. All significant miRNAs had a lower level of expression in splenic marginal zone lymphoma than in other B-cell lymphomas. Thus, miR-21 expression in splenic marginal zone lymphoma was a half that in follicular lymphoma and mantle cell lymphoma (Table 2; Figure 5).

\section{Validation of Microarray Data in an Independent Formalin-Fixed, Paraffin-Embedded Series}

Microarray results were validated by a quantitative RT-PCR assay in an independent formalin-fixed, paraffin-embedded series. The set of miRNAs selected for validation by quantitative RT-PCR was a combination of those found to be differentially expressed in the previous analysis, including miR21, miR-155, miR-193b, miR-29c, miR-27b, miR-377, miR-145 and miR-660 (Table 2).

The quantitative RT-PCR analysis confirmed higher expression levels in splenic marginal zone lymphoma versus reactive spleen of miR-21, miR155 and $\operatorname{miR}-193 b$, and a lower level of $m i R-27 b$, miR-377 and miR-145, with significant $P$-values for all miRNAs except for miR-193b. The differential expression between splenic marginal zone lymphoma and the other B-cell lymphomas in the spleen was also confirmed for miR-21 and miR-660. Full results are shown in Figure 6.

\section{Discussion}

The lack of specific markers in splenic marginal zone lymphoma is an obstacle to its diagnosis,

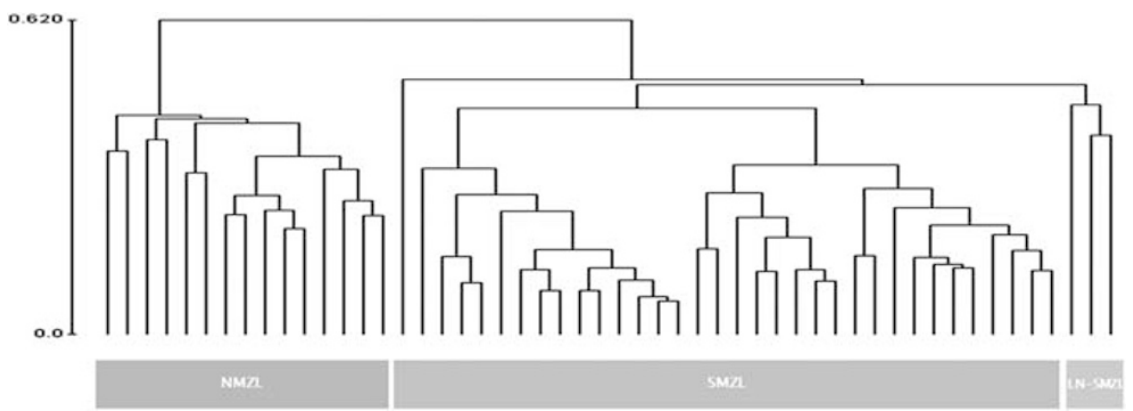

Figure 4 Splenic marginal zone lymphoma miRNA signature. Supervised clustering of splenic marginal zone lymphoma miRNA signature was able to discriminate between splenic marginal zone lymphoma cases in the spleen, lymph node infiltrated by splenic marginal zone lymphoma (LN-SMZL) and nodal marginal zone lymphoma (NMZL). Splenic marginal zone lymphoma cases in the spleen or lymph node appear clustered in comparison with nodal marginal zone lymphoma. The cluster was derived in the GEPAS 4.0 analysis suite (http://gepas.bioinfo.cipf.es/) using the SOTA algorithm. Significance was that associated with the Pearson correlation coefficient. 

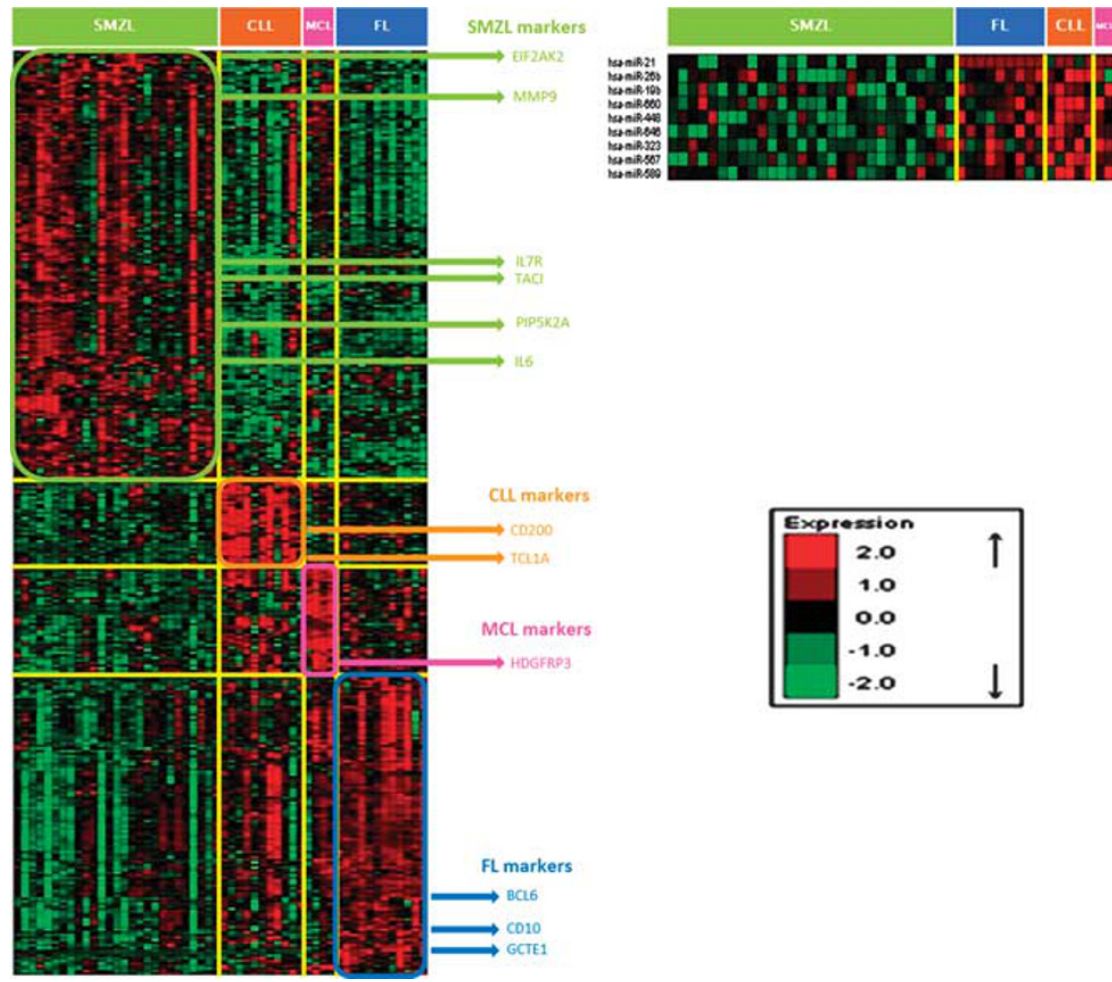

Figure 5 Splenic marginal zone lymphoma expression patterns with respect to other low-grade B-cell lymphomas: miRNAs and GEP. Hierarchical clustering of genes with FDR $<0.05$ and -1 - to 1 -fold change, and miRNAs with FDR $<0.05$ and -0.85 - to 0.85 -fold change. Splenic marginal zone lymphoma cases were compared with other lymphoma samples (follicular lymphoma, chronic lymphocytic leukemia and mantle cell lymphoma, all treated as a single class) using a $t$-test (http://pomelo2.bioinfo.cnio.es/). Some relevant genes are indicated with arrows.

especially in those cases where the diagnosis is required to be made from bone marrow or peripheral blood, but without information about the splenic histology. In the present work, we have investigated the GEP and miRNA expression pattern in a splenic marginal zone lymphoma series selected using highly conservative diagnostic criteria. This approach reduced the number of cases that could be analyzed but improved the chance of identifying consistent and specific molecular markers. Cases with intermediate properties or insufficient clinical data were excluded from the analysis.

The close similarity of the gene expression and miRNA profiles in the splenic marginal zone lymphoma series suggests that this disorder is a unique entity and highlights the homogeneity of our data. The miRNA expression profile in splenic marginal zone lymphoma comprises miRNAs regulating important B-cell pathways such as NF- $\kappa \mathrm{B}$ signaling, CD40 signaling, interleukins (IL2, IL6, IL12), inflammatory pathways and memory B-cellrelated pathways. These findings confirm the similarity of splenic marginal zone lymphoma with the marginal zone. ${ }^{12,24-26}$ As already described in other low-grade lymphomas, ${ }^{16}$ the inflammatory cytokines present in the microenvironment may be involved in the onset and progression of disease contributing to the survival of tumor cells, consistently with what is already known about the role of the inflammatory microenvironment in this lymphoma type.

Comparison of the miRNA signatures of splenic and nodal marginal lymphomas show that both entities differ in the expression of a group of selected miRNAs. Interestingly, lymph nodes infiltrated by splenic marginal zone lymphoma seem to cluster with spleens infiltrated by splenic marginal zone lymphoma in comparison with nodal marginal zone lymphoma, thus suggesting that splenic marginal zone lymphoma can be distinguished from disseminated nodal marginal zone lymphoma cases. Therefore, although these data require a further validation in a larger series, the two diseases seem represent separate entities, not just different stages of the same disorder.

We found previously described miRNAs forming part of the splenic marginal zone lymphoma signature that were deregulated in this lymphoma type, such as the overexpressed miR-21, miR-34a and $m i R-155$, the repressed $m i R-139,{ }^{15}$ and miRNAs deregulated in other tumors, such as miR-21, ${ }^{27-30}$ miR-34a ${ }^{31}$ and miR-193b. ${ }^{32}$ The most significant miRNAs observed in the splenic marginal zone lymphoma signature were miR-155, miR-34a, miR193b, miR-21, miR-377, miR-376a, miR-27b and miR-145. The expression pattern of these miRNAs has been previously reported in the different B-cell stages, so that miR-155, miR-34a and miR-193b were 

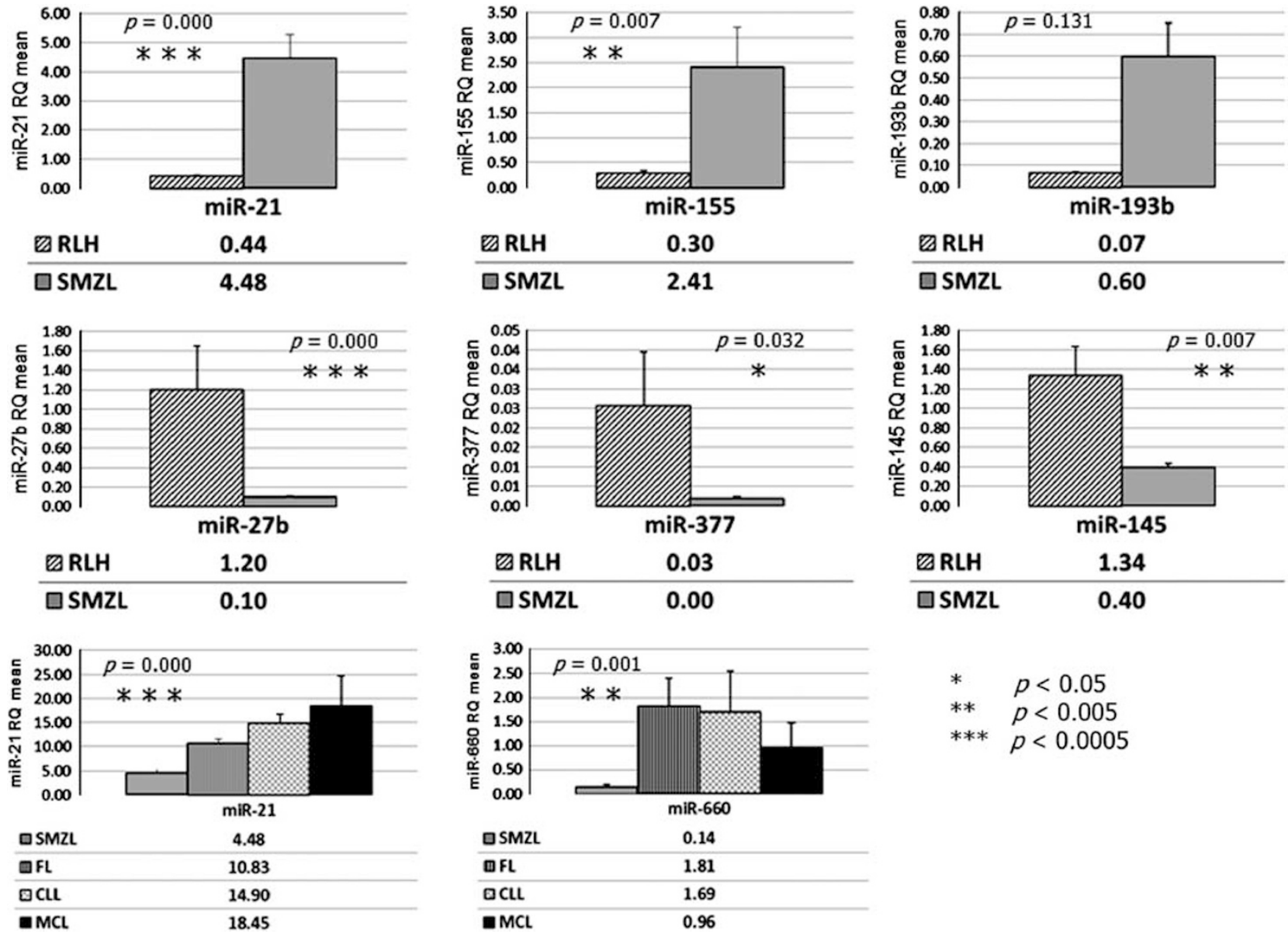

$$
\begin{array}{ll}
* & p<0.05 \\
* * & p<0.005 \\
\text { *** } & p<0.0005
\end{array}
$$

Figure 6 Quantitative RT-PCR assay for miRNAs. Expression data (mean RQ) of the validated quantitative RT-PCR miRNAs included in the splenic marginal zone lymphoma signature compared with reactive spleen and other low-grade B-cell lymphomas (follicular lymphoma, chronic lymphocytic leukemia and mantle cell lymphoma). RQ values are shown below the corresponding graph, and the $P$-values associated with $t$-tests are shown on the bars for each comparison. The miRNAs provided valuable data in the quantitative RT-PCR assay with values of $\mathrm{Ct}<32$. Oblique hatching represents reactive spleen (RLH) cases; light gray, splenic marginal zone lymphoma (SMZL) cases; vertical hatching, follicular lymphoma (FL) cases; cross-hatching, chronic lymphocytic leukemia (CLL) cases; and black, mantle cell lymphoma (MCL) cases.

found overexpressed in memory $B$ cells, the converse of what is found in naive $B$ cells. ${ }^{12}$ MiR-21 has a higher level of expression in memory cells than in both naive and germinal center cells, ${ }^{12,13,25}$ miR-145 is more weakly expressed in memory than in naive $\mathrm{B}$ cells, ${ }^{25}$ and miR-27b has recently been described as being downregulated in memory B cells relative to both naive and GC B cells. ${ }^{12,25}$ In addition, miR-21, miR-193b and miR$34 a$ were upregulated in splenic marginal zone lymphoma B cells relative to normal B cells in this series. Thus, the miRNome of splenic marginal zone lymphoma determined in the present study suggests that this tumor is a neoplastic expansion of memory B cells, similar to what our group has observed for nodal marginal zone lymphoma. ${ }^{16}$

Our findings confirm the increased expression of miR-155 in splenic marginal zone lymphoma ${ }^{15}$ and other lymphoid neoplasias. ${ }^{27-29,33}$ MiR-155 is involved in the development of different B-cell differentiation stages ${ }^{34}$ and helps regulate essential immune functions. ${ }^{35}$ Also, miR-155 targets the PLEKHG5 gene, which is involved in the NF- $\kappa \mathrm{B}$ signaling pathway, ${ }^{36}$ and thus miR-155 could be involved in NF- $\kappa \mathrm{B}$ upregulation in splenic marginal zone lymphoma. The splenic marginal zone lymphoma signature contains others relevant overexpressed miRNAs, such as miR-34a and miR$193 b$, which are upregulated in cancer, miR-34a in chronic lymphocytic leukemia ${ }^{31}$ and miR-193b in malignant melanoma. ${ }^{32}$ These miRNAs have a predicted target in the TNFAIP1 gene and could therefore regulate this gene. TNFAIP1 was repressed in our splenic marginal zone lymphoma series and has been described as an apoptosis regulator, ${ }^{37}$ so that overexpression of miR-34a and miR-193b could be involved in regulating apoptosis in splenic marginal zone lymphoma cells, via TNFAIP1.

MiR-21 is one of the miRNAs most closely related to lymphoma development, and is overexpressed in chronic lymphocytic leukemia, ${ }^{27}$ diffuse large B-cell lymphoma, ${ }^{28}$ acute myeloid leukemia, ${ }^{30}$ Hodgkin 
lymphoma ${ }^{29}$ and other diseases. The TSPYL5 gene, which is involved in PTEN-AKT signaling, is a target of miR-21 and could be regulated by this miRNA. The overexpression of miR-21 could be responsible for TSPYL5 suppression, resulting in PTEN cellular deregulation, followed by changes in AKT activation. This TSPYL5 suppression could also determine the expression level of p21 and subsequently induce deregulation of cell growth. ${ }^{38}$ Thus, the upregulation of this oncogenic miRNA could contribute to the onset and progression of this lymphoma type.

$\mathrm{RHOH}$ and AIM2, which have oncogenic activity and are upregulated in splenic marginal zone lymphoma, ${ }^{9}$ could be overexpressed as a consequence of the downregulation of $m i R-27 b$, as the loss of miR-145 could allow the upregulation of the splenic marginal zone lymphoma-relevant integrin $C D 40$. The relevance of genes regulated by these two miRNAs in splenic marginal zone lymphoma suggests that the loss of miR-27b and miR-145 may contribute to this lymphoma subtype.

The enrichment of relevant pathways involved in B-cell survival, like NF- $\kappa$ B, CD40 and interleukins, and cancer-related pathways, such as RHO, TNFR and JAK-STAT, is correlated with the upregulation of miRNAs, such as miR-155, miR-21 and miR-34a in this series of cases, suggesting that the concerted regulation of these miRNAs could help regulate these pathways and thereby contribute to the survival of lymphoma cells.

Although the miRNA signature of SMZL does not include miRNAs located in 7q32, when we compared the miRNA expression of $\mathrm{B}$ cells from splenic marginal zone lymphoma patients with those from healthy donors, we found two repressed miRNAs, miR-29b and miR-592, located in 7q32. This is consistent with the loss of this band in the splenic subtype of marginal zone lymphoma and with previous observations. ${ }^{4,5}$ Moreover, the expression of miRNAs may be subject to regulatory mechanisms independent of the loss in 7q, such as methylation and histone modification.

Comparison of the miRNA expression pattern in splenic marginal zone lymphoma and other low-grade B-cell lymphomas when the spleen is involved revealed a set of 9 miRNAs with statistically differential expression between the two groups. Of these, 3 were already known to be deregulated in lymphoma cells: miR-21, miR-19b and miR-660. In malignant lymphoma, an miRNA study found genomic upregulation of miR-19b, ${ }^{39}$ while miR-660 was found to be upregulated in leukemic cells ${ }^{40}$ and miR-21 has been described in cancer on several occasions. ${ }^{27,28,30}$ Similarly, GEPs from follicular lymphoma, chronic lymphocytic leukemia and mantle cell lymphoma involving the spleen compared with the splenic marginal zone lymphoma GEP showed overexpression of known markers and of previously described genes. The discovery of additional genes in the context of other lymphomas is consistent with our results, eg, $C D 200^{41}$ and $T C L 1 A^{42}$ in chronic lymphocytic leukemia, $H D G F R P 3^{43}$ in mantle cell lymphoma, and germinal center markers such as BCL6, CD10 and GCTE1 in follicular lymphoma. The genes and miRNAs found in other lymphomas support our data in splenic marginal zone lymphoma, which include those from genes related to normal marginal zone (TACI), interleukins $(I L 6, I L 7 R)$ and several interesting kinases, such as PIP5K2A and EIF2AK2. $P I P 5 K 2 A$ is a second messenger that regulates the levels of phosphatidylinositol by increasing $A K T$ activity ${ }^{44}$ and $E I F 2 A K 2$ is a kinase that takes part in regulating protein synthesis. ${ }^{45}$ Lastly, we also found genes, such as $M M P 9$, that have previously been described in the splenic marginal zone lymphoma GEP. ${ }^{9}$

Our study did not set out to identify the causes of the changes in the expression of the miRNAs identified. The miRNA splenic marginal zone lymphoma signature contains several downregulated miRNAs located in 14q32, including miR$376 a$ and miR-377 among others, which are lost in splenic marginal zone lymphoma compared with non-tumoral spleen and other low-grade B-cell lymphomas. The finding is consistent with the recently published results showing $14 \mathrm{q}$ alterations in splenic marginal zone lymphoma, ${ }^{6}$ which are also associated with poor prognosis. ${ }^{46}$ Downregulation of these miRNAs could also be involved in the growth and progression of splenic marginal zone lymphoma through the regulation of oncogenic target genes such as MUM1, FOXP1, SYK and BCL2.

In summary, the present study shows that the splenic marginal zone lymphoma miRNA expression profile reproduces the normal marginal zone and memory B-cell program. The most relevant miRNAs of the signature have target genes involved in some of the most important pathways involved in the splenic marginal zone lymphoma pathogenesis, such as NF- $\kappa \mathrm{B}$ and CD40 pathways, and thus could be deregulated through the concerted action of these miRNAs in splenic marginal zone lymphoma.

\section{Acknowledgements}

We thank the Tumor Bank of the Hospital Virgen de la Salud (BioB-HVS) and the CNIO Tumour Bank (Madrid) for kindly providing the cases included in this series. We also thank G Gómez (CNIO) and $S$ Opazo (HVS) for their excellent technical help. This study was supported by grants from the Ministerio de Sanidad y Consumo (RETICS, PI081666, INT10/080), the Ministerio de Ciencia e Innovacion (SAF2008-03871), the Servicio de Salud de Castilla la Mancha (FISCAM PI2008/31) and the Asociación Española Contra el Cancer (AECC). MSB was supported by a Miguel Servet contract from the Fondo de Investigaciones Sanitarias, Ministerio de Sanidad y Consumo, Spain. 


\section{Disclosure/conflict of interest}

The authors declare no conflict of interest.

\section{References}

1 Swerdlow SH, Campo E, Harris NL, et al. WHO Classification of Tumours of Haematpoietic and Lymphoid Tissues. International Agency for Research on Cancer (IARC): Lyon; 2008; ch 10: pp 185-187.

2 Mateo M, Mollejo M, Villuendas R, et al. 7q31-32 allelic loss is a frequent finding in splenic marginal zone lymphoma. Am J Pathol 1999;154:1583-1589.

3 Rinaldi A, Mian M, Chigrinova E, et al. Genome-wide DNA profiling of marginal zone lymphomas identifies subtype-specific lesions with an impact on the clinical outcome. Blood 2011;117:1595-1604.

4 Watkins AJ, Hamoudi RA, Zeng N, et al. An integrated genomic and expression analysis of $7 q$ deletion in splenic marginal zone lymphoma. PLoS One 2012;7: e44997.

5 Ruiz-Ballesteros E, Mollejo M, Mateo M, et al. MicroRNA losses in the frequently deleted region of 7q in SMZL. Leukemia 2007;21:2547-2549.

6 Baró C, Salido M, Espinet B, et al. New chromosomal alterations in a series of 23 splenic marginal zone lymphoma patients revealed by Spectral Karyotyping (SKY). Leuk Res 2008;32:727-736.

7 Harris NL, Jaffe ES, Diebold J, et al. The World Health Organization classification of neoplastic diseases of the haematopoietic and lymphoid tissues: Report of the Clinical Advisory Committee Meeting, Airlie House, Virginia, November 1997. Histopathology 2000;36:69-86.

8 Algara P, Mateo MS, Sanchez-Beato M, et al. Analysis of the $\operatorname{IgV}(\mathrm{H})$ somatic mutations in splenic marginal zone lymphoma defines a group of unmutated cases with frequent $7 \mathrm{q}$ deletion and adverse clinical course. Blood 2002;99:1299-1304.

9 Ruiz-Ballesteros E, Mollejo M, Rodriguez A, et al. Splenic marginal zone lymphoma: proposal of new diagnostic and prognostic markers identified after tissue and cDNA microarray analysis. Blood 2005;106: 1831-1838.

10 Rossi D, Trifonov V, Fangazio M, et al. The coding genome of splenic marginal zone lymphoma: activation of NOTCH2 and other pathways regulating marginal zone development. J Exp Med 2012;209: 1537-1551.

11 Kiel MJ, Velusamy T, Betz BL, et al. Whole-genome sequencing identifies recurrent somatic NOTCH2 mutations in splenic marginal zone lymphoma. J Exp Med 2012;209:1553-1565.

12 Basso K, Sumazin P, Morozov P, et al. Identification of the human mature B cell miRNome. Immunity 2009;30:744-752.

13 Jima DD, Zhang J, Jacobs C, et al. Deep sequencing of the small RNA transcriptome of normal and malignant human B cells identifies hundreds of novel microRNAs. Blood 2010;116:e118-e127.

14 Bouteloup M, Verney A, Rachinel N, et al. MicroRNA expression profile in splenic marginal zone lymphoma. Br J Haematol 2012;156:279-281.

15 Peveling-Oberhag J, Crisman G, Schmidt A, et al. Dysregulation of global microRNA expression in splenic marginal zone lymphoma and influence of chronic hepatitis $\mathrm{C}$ virus infection. Leukemia 2012;26:1654-1662.

16 Arribas AJ, Campos-Martín Y, Gómez-Abad C, et al. Nodal marginal zone lymphoma: gene expression and miRNA profiling identify diagnostic markers and potential therapeutic targets. Blood 2012;119:e9-e21.

17 Rodríguez A, Villuendas R, Yáñez L, et al. Molecular heterogeneity in chronic lymphocytic leukemia is dependent on BCR signaling: clinical correlation. Leukemia 2007;21:1984-1991.

18 Ach RA, Wang H, Curry B. Measuring microRNAs: comparisons of microarray and quantitative PCR measurements, and of different total RNA prep methods. BMC Biotechnol 2008;8:69.

19 Ritchie ME, Silver J, Oshlack A, et al. A comparison of background correction methods for two-colour microarrays. Bioinformatics 2007;23:2700-2707.

20 Aggarwal M, Sánchez-Beato M, Gómez-López G, et al. Functional signatures identified in B-cell non-Hodgkin lymphoma profiles. Leuk Lymphoma 2009;50: 1699-1708.

21 Di Lisio L, Gómez-López G, Sánchez-Beato M, et al. Mantle cell lymphoma: transcriptional regulation by microRNAs. Leukemia 2010;24:1335-1342.

22 Troen G, Nygaard V, Jenssen TK, et al. Constitutive expression of the AP-1 transcription factors $\mathrm{c}$-jun, junD, junB, and c-fos and the marginal zone B-cell transcription factor Notch2 in splenic marginal zone lymphoma. J Mol Diagn 2004;6:297-307.

23 Thieblemont C, Coiffier B. Management of marginal zone lymphomas. Curr Treat Options Oncol 2006;7: 213-222.

24 Shen Y, Iqbal J, Xiao L, et al. Distinct gene expression profiles in different B-cell compartments in human peripheral lymphoid organs. BMC Immunol 2004;5:20.

25 Tan LP, Wang M, Robertus JL, et al. miRNA profiling of B-cell subsets: specific miRNA profile for germinal center B cells with variation between centroblasts and centrocytes. Lab Invest 2009;89:708-716.

26 Weill JC, Weller S, Reynaud CA. Human marginal zone B cells. Annu Rev Immunol 2009;27:267-285.

27 Fulci V, Chiaretti S, Goldoni M, et al. Quantitative technologies establish a novel microRNA profile of chronic lymphocytic leukemia. Blood 2007;109: 4944-4951.

28 Lawrie CH, Gal S, Dunlop HM, et al. Detection of elevated levels of tumour-associated microRNAs in serum of patients with diffuse large B-cell lymphoma. Br J Haematol 2008;141:672-675.

29 Van Vlierberghe P, De Weer A, Mestdagh $\mathrm{P}$, et al. Comparison of miRNA profiles of microdissected Hodgkin/Reed-Sternberg cells and Hodgkin cell lines versus $\mathrm{CD} 77+\mathrm{B}$-cells reveals a distinct subset of differentially expressed miRNAs. Br J Haematol 2009;147:686-690.

$30 \mathrm{Mi} \mathrm{S}$, Lu J, Sun M, et al. MicroRNA expression signatures accurately discriminate acute lymphoblastic leukemia from acute myeloid leukemia. Proc Natl Acad Sci USA 2007;104:19971-19976.

31 Asslaber D, Piñón JD, Seyfried I, et al. microRNA-34a expression correlates with MDM2 SNP309 polymorphism and treatment-free survival in chronic lymphocytic leukemia. Blood 2010;115:4191-4197.

32 Caramuta S, Egyházi S, Rodolfo M, et al. MicroRNA expression profiles associated with mutational status and survival in malignant melanoma. J Invest Dermatol 2010;130:2062-2070. 
33 Roehle A, Hoefig KP, Repsilber D, et al. MicroRNA signatures characterize diffuse large B-cell lymphomas and follicular lymphomas. Br J Haematol 2008;142: 732-744.

34 Thai TH, Calado DP, Casola S, et al. Regulation of the germinal center response by microRNA-155. Science 2007;316:604-608.

35 Pauley KM, Cha S, Chan EK. MicroRNA in autoimmunity and autoimmune diseases. J Autoimmun 2009;32: 189-194.

36 Matsuda A, Suzuki Y, Honda G, et al. Large-scale identification and characterization of human genes that activate NF-kappaB and MAPK signaling pathways. Oncogene 2003;22:3307-3318.

37 Kim DM, Chung KS, Choi SJ, et al. RhoB induces apoptosis via direct interaction with TNFAIP1 in HeLa cells. Int J Cancer 2009;125:2520-2527.

38 Kim EJ, Lee SY, Kim TR, et al. TSPYL5 is involved in cell growth and the resistance to radiation in A549 cells via the regulation of p21(WAF1/Cip1) and PTEN/AKT pathway. Biochem Biophys Res Commun 2010;392:448-453.

39 Tagawa H, Seto M. A microRNA cluster as a target of genomic amplification in malignant lymphoma. Leukemia 2005;19:2013-2016.

40 Pizzimenti S, Ferracin M, Sabbioni S, et al. MicroRNA expression changes during human leukemic HL-60 cell differentiation induced by 4-hydroxynonenal, a product of lipid peroxidation. Free Radic Biol Med 2009;46:282-288.

41 El Desoukey NA, Afify RA, Amin DG, et al. CD200 expression in B-cell chronic lymphoproliferative disorders. J Investig Med 2012;60:56-61.

42 Calin GA, Pekarsky Y, Croce CM. The role of microRNA and other non-coding RNA in the pathogenesis of chronic lymphocytic leukemia. Best Pract Res Clin Haematol 2007;20:425-437.

43 Ortega-Paino E, Fransson J, Ek S, et al. Functionally associated targets in mantle cell lymphoma as defined by DNA microarrays and RNA interference. Blood 2008;111:1617-1624.

44 Wilcox A, Hinchliffe KA. Regulation of extranuclear PtdIns5P production by phosphatidylinositol phosphate 4-kinase 2alpha. FEBS Lett 2008;582: 1391-1394.

45 Yoon CH, Miah MA, Kim KP, et al. New Cdc2 Tyr 4 phosphorylation by dsRNA-activated protein kinase triggers Cdc2 polyubiquitination and G2 arrest under genotoxic stresses. EMBO Rep 2010;11:393-399.

46 Salido M, Baró C, Oscier D, et al. Cytogenetic aberrations and their prognostic value in a series of 330 splenic marginal zone B-cell lymphomas: a multicenter study of the Splenic B-Cell Lymphoma Group. Blood 2010;116:1479-1488.

Supplementary Information accompanies the paper on Modern Pathology website (http://www.nature.com/ modpathol) 